\title{
A REVOLUÇÃO BURGUESA NO BRASIL: ESBOÇO DE UMA CRÍTICA
}

\section{THE BOURGEOIS REVOLUTION IN BRAZIL: OUTLINE OF A REVIEW}

\author{
Emmanoel Lima Ferreira ${ }^{1}$ \\ Kátia Regina Rodrigues Lima ${ }^{2}$ \\ Frederico Jorge Ferreira Costa ${ }^{3}$ \\ Maria do Socorro Lima Costa ${ }^{4}$
}

\section{RESUMO}

Este artigo objetiva fazer um esboço analítico da obra A Revolução Burguesa no Brasil, de Florestan Fernandes, considerado por muitos como seu principal trabalho. Foi utilizada a metodologia da leitura imanente e da pesquisa teórica. O objetivo centra-se na vitalidade do pensamento do autor para a compreensão da realidade nacional. $\mathrm{O}$ texto divide-se em três momentos. O primeiro destaca identificação, por parte de Florestan Fernandes, da especificidade da nossa formação nacional. O segundo indica as polêmicas e críticas em torno da compreensão da singularidade do desenvolvimento do capitalismo no Brasil posta por Florestan Fernandes. Por fim, pontuamos alguns tópicos analíticos de Florestan Fernandes sobre o golpe de 1964 e o regime militar.

PALAVRAS-CHAVE: Florestan Fernandes - Revolução Burguesa - Brasil.

\begin{abstract}
This article aims to make an analytical outline of the book The Bourgeois Revolution in Brazil, of Florestan Fernandes, considered by many as their main job. The methodology of immanent reading and theoretical research was used. The objective focuses on the vitality of the author's thought to the understanding of the national reality. The text is divided into three stages. The first highlights identification, by Florestan Fernandes, the specific nature of our national formation. The second indicates the controversies and criticisms around the understanding of the development of capitalism in Brazil put uniqueness by Florestan Fernandes. Finally, we pointed out some analytical topics of Florestan Fernandes about the 1964 coup and the military regime.
\end{abstract}

KEYWORDS: Florestan Fernandes - Bourgeois Revolution - Brazil. 
... Retomei, no Guarujá e em Itanhaém, o trabalho sobre revolução burguesa no Brasil. Redigira um largo capítulo, em 1966 (o qual então passei a máquina); e tinha uma parte de outro capítulo sobre a emergência da ordem social competitiva. Todavia, o assunto não me atrai tanto, em nossos dias. Bati a máquina o que escrevera sobre o elemento competitivo na antiga ordem escravocrata e senhorial - mas não vou terminar o capítulo. Vou deixar como está, largado às urtigas a análise de como a ordem social competitiva emergiu historicamente. Quem precisa saber isso, em nossos pobres dias? Em compensação, vou escrever um capítulo novo, sobre as características da hegemonia burguesa no período da intensificação da industrialização. Junto os três capítulos, publicando o livro desse jeito (e não de acordo com o plano inicial, que era mais extenso e complexo. Penso que é o bastante, pois a revolução burguesa "já foi”...

Fico por aqui, enviando-lhe o meu enternecido carinho.

Que seria de carinho sem amor? (Florestan Fernandes)

\section{INTRODUÇÃO}

Neste vigésimo ano sem Florestan Fernandes (1920-1995), este artigo expressa o resultado parcial de um conjunto de reflexões desenvolvidas pelo intercâmbio de grupos de pesquisas de duas universidades em torno de autores e obras seminais das ciências humanas no Brasil que reverberem numa inteligibilidade da problemática educacional nacional.

Assim, este artigo objetiva fazer um esboço analítico da obra A Revolução Burguesa no Brasil, de Florestan Fernandes, considerado por muitos como seu principal trabalho, mostrando a vitalidade do pensamento do autor para a compreensão da realidade nacional enquanto totalidade concreta, ou seja, como síntese contraditória de inúmeras determinações históricas, sociais, econômicas e culturais.

Sartre asseverou que a segunda Guerra Mundial foi um "divisor de águas" para a intelectualidade francesa. O golpe militar também pode ser comparado, guardando as devidas proporções, a um divisor de águas para a intelectualidade brasileira. Parafraseando Florestan, o regime militar colocou a luta de classes a quente, retirando as liberdades democráticas e impedindo o trabalho de uma plêiade de intelectuais nas universidades, principalmente o de Florestan Fernandes.

Florestan passou pelo Partido Socialista Revolucionário-PSR, uma pequena organização trotskista. Embora já sendo um intelectual reconhecido, jamais escondeu ou renegou sua origem social ${ }^{5}$. 
Enquanto Caio Prado Júnior (1907-1990) já havia conhecido a Europa e estudara na Inglaterra, aos 13 ou 14 anos já lia bem em inglês e francês, Florestan só foi se assenhorear de outras línguas na universidade, estudando diversas horas por dia para suprir sua deficiência na leitura dos clássicos e de outras línguas.

Isso demonstra a capacidade de trabalho que chegou a impressionar muitos colegas seus e que o permitiu ser um elemento aglutinador e formador de jovens professores e pesquisadores, como Fernando Henrique, Otavio Ianni e outros. O próprio Fernando Henrique disse numa entrevista à TV Câmara que o que lhe chamou mais a atenção foi a "devoção e o rigor com que ele se dedicava ao trabalho acadêmico'. (CERQUEIRA, 2004, p. 36).

\section{FLORESTAN FERNANDES E A ESPECIFICIDADE DE NOSSO DESENVOLVIMENTO}

Bárbara Freitag correspondeu-se com Florestan Fernandes durante o exílio e no período anterior a morte dele. Pretendia escrever um trabalho sobre Florestan e, quando o fez, dividiu a produção desse autor em dois momentos — o acadêmico reformista e o político revolucionário. O reformista foi até 1969 e o revolucionário após o AI-5. A distinção entre os dois períodos é marcada pelas teorias que informaram os escritos do autor ora focalizado. No primeiro período, houve influência marcante de Karl Mannheim, Durkheim, Weber, Marx etc. Na segunda fase, uma ascendência mais nítida de Marx e de marxistas como Lênin e Trotsky ${ }^{6}$.

Há sociólogos que preferem o Florestan da primeira quadra, por separar juízo de fato e juízo de valor. Bem, uma coisa é indubitável: Florestan jamais abjurou de suas ideias ou se adequou ao dito do Presidente operário convertido às benesses do poder e do grande capital - que é compreensível um jovem esquerdista, mas um senhor esquerdista seria uma sandice. Florestan continuou de esquerda até sua morte e já esboçava críticas a vários aspectos no Partido dos Trabalhadores, que o desagradavam sobremaneira - ter como eixo central de atividade o Parlamento, por exemplo. Infelizmente em decorrência de um erro médico, Florestan contraiu uma doença que o combaliu muito até ceifar sua vida. Florestan, particularmente no segundo momento, não separava, com uma muralha da China, juízo de fato e juízo de valor ou ciências 
nomotéticas e ciências ideográficas. No prefácio à segunda edição do seu livro $A$ Revolução Burguesa no Brasil, ele escreveu:

\begin{abstract}
Essas reflexões revelam que não fiquei parado. De um lado, continuei a procurar um melhor entendimento entre sociologia e história. Já houve quem dissesse que a sociologia é uma história mal feita. O autor dessa afirmação ouviu, como réplica, que a história é uma sociologia frustrada... Se me volto, de modo tão incisivo, para os processos de longa duração, faço isso porque esse é o traço lógico sine qua non da sociologia diferencial (ou histórica), de Marx aos nossos dias. É claro que alguns sociólogos se concentraram em fases de curta duração - e é incontestável que a maioria dos sociólogos prefere, pura e simplesmente, omitir o fluxo da história através da pesquisa de campo focalizada no tempo in flux de pequenos grupos ou de instituições ou no tempo psicológico da motivação das atitudes e comportamentos humanos. Não obstante, esse nunca foi o meu caminho. Se ao estudar os tupinambá fiquei confinado à reconstrução histórica firmemente delimitada, o esforço que fiz para chegar a explicações gerais, ou seja, ao conhecimento de uma civilização, como diária Mauss, é patente. Se ao estudar o folclore paulistano fiquei preso à órbita estreita de uma pesquisa de campo, também é evidente que procurei transcender às fronteiras do imediato... (FERNANDES, 1981, p. 9-10).
\end{abstract}

Coutinho (2000) assevera que Florestan é um dos poucos intelectuais que formularam uma imagem do Brasil e que imagens desse tipo sempre articulam juízos de fato e discernimentos de valor, vale dizer, consoante Coutinho, tais imagens articulam o ser e o dever ser.

Na avaliação de Saes (2001), Florestan, em A Revolução Burguesa no Brasil, não ficou enredado num falso dilema que parece martirizar tantos pesquisadores hoje em dia - fazer micro ou macrossociologia. Entende Saes que Florestan jamais incorreu nesse dilema, pois sua obra sempre se pautou por múltiplos interesses e variados campos disciplinares — "etnografia, teoria sociológica, sociologia histórica" —, e destaca a importância do trabalho de Fernandes pelos seguintes aspectos:

Mirar-se hoje no exemplo intelectual de Florestan Fernandes implica: a) reafirmar a legitimidade do trabalho de interpretação macrossociológica do processo histórico brasileiro e incentivar a aparição de novos esquemas interpretativos, bem como contribuir para o cotejo das suas diferenças; b) reconhecer que essa empreitada está longe de significar a deslegitimação de todo - sempre necessário — de investigação empírica ou microssociológica (reconhecimento esse que não acarreta, esclareça-se logo, concordância com as premissas teóricas de todo trabalho desse tipo); c) valorizar a interação dinâmica ente esses dois tipos de trabalho (SAES, 2001, p. 19). 
Certamente, a obra A Revolução Burguesa no Brasil é uma tentativa de explicar a especificidade do desenvolvimento do capitalismo no Brasil e os traços profundamente antidemocráticos, de nossa burguesia, que se apresentavam sem nenhum pudor com o golpe de 1964. Ele começou a escrever o livro em 1966 e foi uma resposta aos desafios expressos pelas novas tarefas que a intelectualidade e o movimento socialista e democrático teriam que defrontar.

A epígrafe utilizada no início deste texto é o trecho de uma carta que Florestan escreveu para Bárbara Freitag em 1973. Nela fica explícito o objetivo da obra que estava sendo gestada e que seria apresentada ao público em 1974, vale dizer, compreender a forma como assumiu o desenvolvimento do capitalismo ou a ordem social competitiva. Figueiredo (2004) destaca em seu livro Modos de ver a Produção do Brasil que Florestan, ao lado de Cardoso de Mello, baliza-se pelo ecletismo. Cohn (1999) frisa que o ecletismo de Florestan é um ecletismo temperado e que só um intelectual do naipe de Florestan poderia fazê-lo com tanta desenvoltura e maestria.

Independentemente do debate sobre o ecletismo ou não da obra e das categorias utilizadas por ele, é sem dúvida uma tarefa monumental, onde fica evidente o longo percurso intelectual do autor e a enorme erudição e conhecimento, não só dos clássicos da Sociologia, como também o pensamento brasileiro.

Para Coutinho (2000), em A Revolução Burguesa no Brasil, o uso de noções weberianas está circunscrita principalmente às partes I e II do livro, escritas em 1966. Na parte III, redigida em 1973-1974, a noção de sociedade estamental desaparece, dando lugar aos conceitos de escravismo colonial, advindos da tradição marxista. Coutinho formula uma hipótese que precisa ser corroborada posteriormente com uma análise mais criteriosa das obras de Fernandes, que é a seguinte: o Sociólogo Paulista aprofundou os estudos sobre marxismo no período de 1966 a 1973.

\section{A SINGULARIDADE DO DESENVOLVIMENTO DO CAPITALISMO NO BRASIL: DEBATES E CRÍTICAS}

Para compreendermos a obra de Florestan, não podemos perder o seu leitmotiv - a singularidade do desenvolvimento do capitalismo no Brasil. Florestan vai demonstrá-lo mediante a gênese de nossa formação socioeconômica e política. Aí está 
para ele a origem de nossa revolução burguesa e esta é abordada na primeira parte do livro, sob o título As Origens da Revolução Burguesa.

Nessa parte, Fernandes faz um ajuste de contas teórico com diversas concepções. Crítica a idéia de que o senhor de engenho pudesse ser assimilado ao burguês pelas suas funções. Para ele, o senhor de engenho ocupava uma posição marginal no processo de mercantilização da produção agrária e não pode ser considerado o antecessor do empresário moderno. Para Fernandes, assim como não tivemos o burgo, também não o feudalismo. Essa é uma crítica dirigida a dois pensadores vinculados ao Partido Comunista Brasileiro (PCB): Caio Prado Júnior ${ }^{7}$ e Nelson Werneck Sodré ${ }^{8}$.

Para Fernandes, quem nega que houve uma revolução burguesa no Brasil busca, na verdade, um caminho semelhante à via clássica de desenvolvimento do capitalismo, ocorrida na Europa, e a transplanta para o Brasil. Para ele a revolução burguesa não era mero episódio histórico, mas um fenômeno estrutural e inscrevia-se na longa gestação da ordem social competitiva.

A Colônia obstaculizou — consoante Florestan Fernandes — as influências que o capitalismo comercial poderia exercer de forma positiva por exaurir os recursos produzidos internamente. O senhor de engenho, para o Sociólogo focalizado, estava mais para um conquistador, um aventureiro, do que para um empreendedor, ou seja, o senhor era mais um soldado da fortuna que encarnava um espírito flibusteiro do que um ladrilhador. Nesse momento, dá para evocar Sérgio Buarque de Holanda, que estabeleceu a antítese entre ladrilhador (espanhol) e semeador (português).

O senhor de engenho, por seu papel secundário, não poderia ter exercido um papel protagonista para as mudanças no País. Coutinho (2000) assevera, com muita propriedade que, tanto na Colônia quanto no Império, a racionalidade que animava os latifundiários escravistas não era capitalista, mas patrimonialista. $\mathrm{O}$ autor assevera que

É precisamente essa correta percepção que lhe permite constatar a emergência, a partir da expansão de relações comerciais na época imperial, de duas novas camadas sociais, a dos fazendeiros de café e a dos imigrantes (RBB, sobretudo 86s.), as quais - embora sem romper inteiramente com a "velha ordem" patrimonialista - começam a agir segundo uma racionalidade propriamente capitalista, o que lhes possibilita desempenhar o papel de protagonistas principais da "revolução burguesa" que se processou em nosso país (COUTINHO, 2000, p. 3). 
A Independência, no longo decurso da revolução burguesa, para Fernandes, foi a primeira grande transformação social que se operou no Brasil, por dois aspectos correlatos: marca o fim da era colonial e é o ponto de referência do surgimento do Estado Nacional.

O liberalismo, para Florestan Fernandes, não é mero ornamento, mas cumpriu um papel importante - foi funcional para as elites se livrarem do fardo colonial que representava a Metrópole e ajudou a formatar, nos campos ideológico, político e jurídico, a configuração do Estado Nacional. Para o autor, embora o liberalismo adotado por nossas elites fosse um liberalismo conspurcado, ele não deixava de cumprir um papel histórico importante. "Por fim, o liberalismo desencadeou uma vaga de idealismo político, que repercutiu de modo construtivo na organização, no funcionamento e no aperfeiçoamento da Monarquia Constitucional (FERNANDES, 1981, p. 38).

A Independência, para Florestan Fernandes, melhorou a posição do senhor rural como agente econômico em face do mercado, mas não retirou o País da situação de heteronomia. A Independência também burocratizou a dominação patrimonialista.

A economia de mercado nacional foi plasmada por volta de 1822. Posteriormente, com a abolição da escravatura, e mais tarde, com a industrialização, o mercado nacional entrou em nova fase cujas características foram a generalização do trabalho livre, a subordinação da agricultura à indústria e o fortalecimento, em meados do século XIX, do poder burguês. Fernandes comenta a dificuldade para datar a consolidação do poder burguês no Brasil, se foi no fim do império ou no começo da república. Vejamos como ele define a revolução burguesa:

$\mathrm{Na}$ acepção em que tomamos o conceito, Revolução Burguesa denota um conjunto de transformações econômicas, tecnológicas, sociais, psicoculturais e políticas que só se realizam quando o desenvolvimento capitalista atinge o clímax de sua evolução industrial (FERNANDES, 1981, p. 202).

A definição conferida por Florestan lembra muito o conceito de Caio Prado Jr. , quando vê a revolução como um processo longo, a tal ponto que o momento de ruptura está praticamente ausente.

Este é o calcanhar-de-aquiles na idéia de revolução burguesa de Fernandes, ou seja, uma revolução burguesa onde a revolução política inexiste. Sobre tal contradição Saes (2001, p. 21) escreveu: 
Pode-se, portanto, dizer que as fórmulas de Fernandes sobre a revolução burguesa ocultam o fato de que entre as duas fases mencionadas da vida econômica de uma sociedade qualquer se interpõe uma revolução política. Voltamos, desse modo, à nossa primeira observação crítica sobre o esquema teórico de Florestan Fernandes: a revolução política não ocupa, aí , nenhum lugar preciso.

Coutinho (2000) ressalta que essa incongruência poderia ter sido evitada se ele trabalhasse com o conceito de via prussiana, de Lênin, ou de revolução passiva, de Gramsci. Coutinho entende que, embora Florestan Fernandes cite várias obras de Lênin na bibliografia, O Programa Agrário da Social Democracia não está presente. Nesse livro, escrito em 1907, o Revolucionário e pensador russo desenvolve esse conceito que seria a via não clássica de desenvolvimento para o capitalismo. A clás sica seria a via americana onde há uma revolução agrária e abre espaço para a forma de domínio democrático da burguesia. A via prussiana foi a via encetada por Alemanha, Japão e Itália. Nesta, o Estado é o protagonista, evitando uma revolução ao estilo popular (jacobino) e a estrutura fundiária é modernizada, mantendo-se inalterada. A segunda via consolida as formas não democráticas de dominação burguesa, em decorrência do peso das forças armadas e do executivo nesta formatação do Estado e da sociedade. Indubitável, porém, é que estes países se tornaram nações centrais do capitalismo mediados pela via prussiana.

Fiori (1995) lembra, com muita propriedade, que a via prussiana é um conceito importante para analisar o Brasil, mas há diferenças substanciais entre a via prussiana dos três países (Alemanha, Japão e Itália) e do Brasil, por exemplo. A via prussiana, para o autor, foi calcada num forte nacionalismo, com militarismo, sob os quais, estes países, principalmente a Alemanha, fizeram sua industrialização com suporte na indústria de bens de produção e de alta tecnologia, à época. Na compreensão de Fiori, em dois períodos no Brasil, tentamos trilhar este caminho: 1) no Estado Novo, de 1937 a 1945, Vargas, aproveitando a disputa interimperialista tentou estabelecer uma indústria de bens de produção, mas foi rechaçado pelas pressões da burguesia nacional e dos Estados Unidos; a moratória da dívida foi suspensa e Vargas teve que retroceder em seu projeto; 2) No II PND, de Geisel, quando os militares procuraram desenvolver uma indústria de bens de produção e criar uma autonomia no campo energético, mas foram novamente sustados nesse projeto pela falta de um sistema financeiro que financiasse essa empreitada, pois os bancos, no Brasil, sempre estiveram mais propensos à 
especulação do que a financiamentos de longo prazo, e pela pressão da burguesia que começou a campanha contra o gigantismo das estatais. No campo internacional, era a assunção da nova direita, com Thatcher e Reagan, ou seja, do neoliberalismo sendo adotado como política governamental. A via prussiana no Brasil não conseguiu lançar o País a um novo patamar de desenvolvimento capitalista. Daí autores como Mazzeo e Chasin formularem o conceito de via prussiana colonial, para entendermos a nossa especificidade.

No exame de Coutinho (2000), se Florestan houvesse empregado o conceito de revolução passiva, teria sido mais profícuo em sua análise sobre a revolução burguesa no Brasil e, segundo o Professor da UFRJ, Fernandes não apreendeu corretamente esse conceito.

\begin{abstract}
Por outro lado, embora o único texto de Gramsci indicado na mencionada bibliografia seja o volume da edição temática dos Cadernos do Cárcere referente a Il Risorgimento — ou seja, precisamente aquele onde estão contidas as principais observações sobre "revolução passiva" - Florestan tampouco se vale desse conceito gramsciano. Mais do que isso. Ele parece não ter apreendido corretamente o sentido dessa noção gramsciana, já que afirma (embora com a cautela de dizer "provavelmente") o seguinte: "se se considerar a Revolução Burguesa na periferia como uma 'revolução frustrada' como fazem muitos autores (provavelmente seguindo implicações da interpretação de Gramsci sobre a revolução burguesa na Itália), é preciso proceder com muito cuidado" (RBB, 294, grifo meu). Na verdade, Gramsci não se refere à "revolução passiva" como uma "revolução frustrada", isto é, fracassada ou inexistente; ao contrário, trata-se para ele de um tipo específico de revolução exitosa, ainda que feita através de conciliações pelo alto e da exclusão do protagonismo popular, o que gera um processo de transformações político-sociais efetivas do qual resulta, em suas palavras, uma "ditadura sem hegemonia" [7]. Ora, é precisamente esse o tipo de revolução burguesa que Florestan julga ter ocorrido no Brasil, sendo evidente, ademais, a analogia entre a "ditadura sem hegemonia" de Gramsci e sua própria noção (sobre a qual voltaremos em seguida) de "autocracia burguesa". Cabe ainda observar que, quando Florestan emprega em sua obra (o que, aliás, faz com freqüência) os termos "hegemonia" e "sociedade civil", nunca os emprega no sentido específico com os mesmos são utilizados na obra de Gramsci (COUTINHO, 2000, p. 2).
\end{abstract}

Um conceito assaz importante para analisar os limites da democracia em nosso País é o de autocracia burguesa, ou seja, a aliança com as oligarquias, para Florestan Fernandes, configurou a dominação burguesa, restringindo ao máximo as possibilidades de uma dominação democrática, ao circunscrever a mentalidade da burguesia aos moldes oligárquicos, mesmo sendo uma oligarquia moderna ou dos altos negócios, para usar uma expressão do próprio Fernandes. 
Para o autor, a crise de 1929 não foi o crepúsculo das oligarquias, mas sua recomposição. Esse restabelecimento das oligarquias marca o início da modernização brasileira. Aqui é importante salientar, no entanto, que Fernandes não tem a mesma concepção de José de Sousa Martins, ao considerar que todos os movimentos importantes no País só ocorreram quando as oligarquias se cindiram, abrindo, então, espaço para o protagonismo popular.

Após a aparente obliteração das oligarquias pela revolta da aliança liberal, as duas oligarquias, a velha e a moderna, ressurgem vigorosamente recauchutadas no Estado Novo. Essa é a debilidade congênita da nossa burguesia, vale dizer, a incapacidade de a burguesia brasileira estabelecer uma hegemonia. Isto significa dizer, como lembra muito bem Coutinho, que a noção de autocracia de Fernandes é muito aparentada ao conceito gramsciano da ditadura sem hegemonia.

Outro fator importante que deixa poucas margens de manobra para Fernandes é o capitalismo dependente. Para ele, a estreita margem de manobra de nossa burguesia decorre da desconexão histórica das necessidades de expansão de nosso mercado e a revolução nacional. Senão vejamos:

\begin{abstract}
Em uma linha objetiva de reflexão crítica, não há como fugir à constatação de que o capitalismo dependente é, por sua natureza e em geral, um capitalismo difícil, o qual deixa apenas poucas alternativas efetivas às burguesias que lhes servem, a um tempo, de parteiras e amas-secas. Desse ângulo, a redução do campo de atuação histórica da burguesia exprime uma realidade específica, a partir da qual a dominação burguesa aparece como conexão histórica não da "revolução nacional e democrática", mas do capitalismo dependente e do tipo de transformação capitalista que ele supõe (FERNANDES, 1981, p. 214).
\end{abstract}

É o modelo neoimperialista de desenvolvimento que se impõe de fora para dentro. Florestan Fernandes (1974) reúne três fases de desenvolvimento do capitalismo no Brasil e ressalta que, em nenhuma das três, houve um desenvolvimento no qual a via democrática se impusesse: $1^{a}$ ) eclosão e emergência do capitalismo moderno. Abrange o período de 1808 a $1860 ; 2^{\mathrm{a}}$ ) formação e expansão do capitalismo competitivo. Período que vai de 1860 a $1950 ; 3^{a}$ ) fase de irrupção do capitalismo monopolista que começa na década de 1950.

$\mathrm{Na}$ primeira quadra, a cidade saiu da sua letargia econômica e passou a centralizar tanto o fluxo e o crescimento do comércio interno quanto à produção 
escravista de maneira geral. Houve uma substituição de produtos importados e uma dupla articulação econômica que jungiu o setor agrário ao mercado mundial.

Na segunda fase, ocorreu a modernização da infraestrutura e de instituições. Também sucedeu, neste entretempo, a formação de certa estrutura industrial e a substituição de produtos importados. Florestan Fernandes destaca a dupla articulação do setor agrário arcaico com a economia internacional. Nesta fase, há a cristalização do capitalismo dependente.

A terceira fase foi de florescimento e propagação do capitalismo monopolista, quando a burguesia atingiu seu ápice no tocante ao poder, potencializando seu caráter autocrático. É a fase da neocolonização suscitada pelas grandes empresas. Para Florestan Fernandes, neste período, a burguesia se vê premida por duas coações: a do aprofundamento da dependência e a exacerbação das desigualdades sociais e econômicas que ensejam instabilidade política. A resposta da burguesia não ocorreu no campo democrático, mas exerceu a luta de classes a quente, impondo o poder das baionetas.

Florestan Fernandes pondera a noção de que não existe uma via apenas para o modelo de transformação capitalista e que, se há o crescimento acelerado da acumulação do capital, a expropriação externa é sempre mantida. Para ele, mesmo que o País crescesse a taxas elevadas e a industrialização fosse se acentuando, a dependência seria também agravada. Nesse caso, o autor lembra muito Caio Prado Júnior, que criticava Juscelino por haver levado a cabo um modelo de industrialização em que o capital estrangeiro era o carro-chefe do processo, aumentando a nossa submissão ao capital estrangeiro.

$\mathrm{Na}$ análise de Florestan Fernandes, também, há uma assimetria ou dissociação na relação crescimento econômico e democracia. A apropriação dual do excedente econômico, de dentro, pela burguesia nacional, e de fora, pelos países imperialistas, acrescida da sobrevivência de relações pré-capitalistas, deixa pouca margem para veleidades democráticas de nossa burguesia. Nesse sentido, o capitalismo dependente é um capitalismo selvagem, utilizando-se de meios de exploração pertinentes à fase de gestação do capitalismo. O Sociólogo acentua ainda que, além desse capitalismo periférico ser selvagem, ele é difícil, ou seja, para sua reprodução, os elementos políticos são cada vez mais essenciais. 
O Estado brasileiro assume cada vez mais a face de uma ditadura de classe preventiva, em decorrência das contradições do nosso desenvolvimento e da incapacidade da burguesia de resolvê-las, apelando para uma revolução democrática e nacional.

O resultado teórico do confronto é óbvio. Ele revelaria que, sob a situação de dependência - tanto sob a dominação neocolonial quanto sob a dominação imperialista — os estratos sociais dominantes e suas elite não possuem autonomia para conduzir e completar a revolução nacional, gravitando historicamente, portanto, de um beco sem saída para outro (FERNANDES, 1981, p. 298)

\section{CONSIDERAÇÕES FINAIS}

Florestan Fernandes define revolução nacional como revolução dentro da ordem compatível com o capitalismo dependente. Para entendemos melhor tal conceito, a revolução nacional, para Lênin e Trotsky, faz parte da revolução democrática. Para Florestan Fernandes, revolução nacional tem a mesma conotação de revolução pelo alto ou revolução passiva na concepção gramsciana.

$\mathrm{Na}$ perspectiva florestaniana (1981), a dupla articulação entre o desenvolvimento desigual interno e a dominação imperialista cria e reforça pontos de estrangulamento estruturais em nossa economia. Florestan Fernandes (1981) exprime a ideação de que o crescimento do Estado no Brasil ocorreu em virtude da fragilidade de nossa burguesia para atuar em diversos campos da economia e, na verdade, o poder estatal para ele é que dinamiza o poder burguês.

O golpe militar de 1964 foi para Florestan Fernandes um movimento preventivo. Em sua análise por demais percuciente, o autor diz que o êxito alcançado pela burguesia era de curto prazo e que a burguesia nacional não engendrou uma dominação mais estável, em longo prazo, pelos fatores inventariados por ele: caráter dependente de nosso capitalismo - que não significa somente dependência cultural e econômica, mas açambarcamento econômico do excedente produzido por diversas formas - e sobrevivência de traços pré-capitalistas, desenvolvimento circunscrito de nossa indústria e limitado a pouca cidades.

Relativamente à ditadura militar, Florestan Fernandes soube analisar as suas fragilidades num momento em que muitos avaliavam que ela veio para durar. Com 
muito acerto, diferenciou os regimes franquista e salazarista do regime militar do Brasil. Os dois primeiros duraram aproximadamente meio século. É verdade que a ditadura durou menos que eles, aproximadamente 21 anos, mas foi tempo suficiente para deixar marcas indeléveis no País e uma delas foi à expulsão de uma gama de intelectuais extremamente refinados, que escreviam pensando em dialogar com a sociedade brasileira para ajudá-la no processo de transformação, das principais universidades e centros de pesquisas. Florestan Fernandes, sem dúvida, foi um dos principais intelectuais atingidos.

Certa vez perguntaram a Atílio Bóron como estava à Sociologia latinoamericana, e este afirmou que a Sociologia estava prêt-à-porter, ou seja, pesquisava de acordo com os modismos da época. Aucustin Cueva (2007) lamentou o conservadorismo da Sociologia latino-americana (que obliterou toda a discussão riquíssima sobre a teoria da dependência) e o declínio da influência marxista nas instituições acadêmicas, num momento em que as formas de opressão desencadeadas pelos sucessivos ajustes fiscais das instituições multilaterais se assemelham muito ao saque colonial perpetrado nesse Continente no início da colonização.

Florestan Fernandes, exilado em Toronto, também asseverou que, para compreender a realidade, não se fazia necessário ler um trabalho de Sociologia, bastava ler um romance ou um jornal, pois tais eram o nível de acriticidade e o grau de especialização dessa ciência. Florestan demonstrou que é possível combinar uma sociologia crítica com pesquisa de primeira linha e uma atuação socialista para transformar a realidade.

\section{REFERÊNCIAS BIBLIOGRÁFIAS}

CERQUEIRA, Laurez. Florestan Fernandes: vida e obra. São Paulo: Expressão Popular, 2004.

CUEVA, Agustín. A Análise "pós-marxista" do Estado latino-americano. Le Monde Diplomatique (Brasil). Ano 1. n 4. nov, 2007.

COHN, Gabriel. A Revolução burguesa no Brasil. IN: MOTA, Lourenço Dantas (Org.). Introdução ao Brasil: um banquete no trópico. 2 ed. São Paulo: Editora SENAC, 1999. 
COUTINHO, Carlos Nelson. Marxismo e "imagem do Brasil" em Florestan

Fernandes. Disponível em http://www.acessa.com/gramsci. Acesso em 10/12/2007.

FERNANDES, Florestan. A Revolução burguesa no Brasil. 3 ed. Rio de Janeiro: Zahar Editores, 1981.

FIGUEIREDO, José Ricardo. Modos de ver a produção do Brasil. São Paulo: Educ; Campinas, SP: Editora Autores Associados, 2004.

FIORI, José Luís. Em Busca do dissenso perdido: ensaios críticos sobre a festejada crise do Estado. Rio de Janeiro: Insight, 1995.

PRADO JÚNIOR, Caio. A revolução brasileira. 5ed. São Paulo: Brasiliense, 1977.

SAES, Décio. Capitalismo e processo político no Brasil. São Paulo: BOITEMPO EDITORIAL, 2001.

SOARES, Eliane Veras. Florestan Fernandes: o militante solitário. São Paulo: Cortez, 1997.

SODRÉ, Nelson Werneck. A formação histórica do Brasil. 8 ed. São Paulo: Brasiliense, 1973.

${ }^{1}$ Doutor em Sociologia. Professor da Universidade Regional do Cariri - URCA. E-mail: emmanoellima@yahoo.com.br

${ }^{2}$ Doutora em Educação. Professora da Universidade Regional do Cariri - URCA. E-mail: kareli20042004@yahoo.com.br

${ }^{3}$ Doutor em Educação. Professor da Universidade Estadual do Ceará - UECE. E-mail: frederico.costa@uece.br.

${ }^{4}$ Mestranda em Educação do Programa de Pós-graduação em Educação - PPGE/UECE. E-mail: socorrolcosta@yahoo.com.br

${ }^{5}$ Florestan era de família humilde; sua mãe trabalhava como lavadeira. 
${ }^{6}$ Conforme Soares (1997) a ruptura epistemológica expressa em sua obra corresponde ao período de seu afastamento compulsório da Universidade de São Paulo-USP em razão do AI-5.

${ }^{7}$ Caio Prado Júnior desenvolveu a tese de um “capitalismo colonial” no Brasil em contraposição a reprodução mecânica por parte do PCB, de que o Brasil teria tido um passado feudal. Ver: PRADO JÚNIOR, Caio. A revolução brasileira. 5 ed. São Paulo: Brasiliense, 1977.

${ }^{8}$ Nelson Werneck Sodré apresentou a teoria de um Brasil escravista com uma regressão feudal. Ver: SODRÉ, Nelson Werneck. A formação histórica do Brasil. 8 ed. São Paulo: Brasiliense, 1973.

RECEBIDO EM: Abril de 2016

APROVADO EM: Junho de 2016 